\title{
De la Doctrina de la Seguridad Nacional a la gobernabilidad migratoria: la idea de seguridad en la normativa migratoria chilena, 1975-2014
}

\author{
María Fernanda Stang \\ Universidad Nacional de Córdoba \\ Email: ferstang@yahoo.com.ar
}

\begin{abstract}
Resumen $^{1}$ : Desde una aproximación inductiva a partir del análisis crítico del discurso, el artículo se propone mostrar la persistencia de la idea de seguridad en el modo en que el Estado chileno ha pensado la migración internacional en las últimas cuatro décadas (entre 1975 y 2014), a través de cuatro textos normativos que se consideran cristalizaciones de ese pensamiento de Estado sobre este proceso social: el decreto ley $\mathrm{N}^{\circ} 1.094$, de 1975 y aún vigente; el proyecto $\mathrm{N}^{\circ} 2891$ de 1993; el instructivo presidencial sobre Política Nacional Migratoria de 2008 y el Proyecto de Ley de Migración y Extranjería N 8970-06, presentado en 2013. Además de mostrar cómo esta idea de seguridad actúa como hilo conductor, también se busca explicar la forma en que este significante se ha ido transformando a lo largo de este período, transitando desde el paradigma de la Doctrina de la Seguridad Nacional al de la gobernabilidad migratoria.
\end{abstract}

Palabras clave: migración internacional, Chile, seguridad, Doctrina de la Seguridad Nacional, gobernabilidad migratoria.

\section{From the Doctrine of National Security to the migration governance: the idea of security in the Chilean migration normative, 1975-2014}

\begin{abstract}
From an inductive approach in the context of critical discourse analysis, the article proposes to show the persistence of the idea of security in the way that the Chilean State has thought international migration in the last four decades (from 1975 to 2014), through four normative texts that are considered crystallizations of that State thought about this social process: Decree Law $\mathrm{N}^{\circ}$ 1.094, of 1975 and still in force; draft law $N^{\circ} 2891$ of 1993; the presidential instruction on National Migration Policy of 2008 and the draft law on migration $\mathrm{N}^{\circ}$ 8970-06, presented in 2013. Along with pointing how this idea of security acts as the guiding thread, the article also seeks to explain the way this significant of security has gone through transformation over this period, moving from the paradigm of National Security Doctrine to that of migration governance.

Key words: international migration; Chile; security; Doctrine of National Security; migration governance.
\end{abstract}




\section{Da Doutrina da Segurança Nacional à governabilidademigratória:a ideia de segurançanasleis de imigração do Chile, 1975-2014}

Resumo: A partir de umaabordagemindutiva da análise crítica do discurso, o artigo se propõe a mostrar a persistência da ideia de segurança na forma como o Estado chileno tempensadoa migração internacional nas últimas quatro décadas (entre 1975 e 2014) através de quatro textos legais que são considerados cristalizações desse pensamento do Estado sobre este processo social: decreto-lei n ${ }^{\circ} 1.094,1975$ e aindaem vigor; o projeto No. 2891 de 1993; a instrução presidencial sobre a política nacional de migração de 2008 e o Projeto de Lei de Migração e Assuntos Estrangeiros No. 8970-06, apresentadoem 2013. Além de mostrar como essaideiade segurançafunciona como um fio condutor, também procura-se explicar a maneira comoesse significante foi transformado ao longo deste período, transitando desde o paradigma da Doutrina da Segurança Nacional para o da governabilidade migratória.

Palavras-chave: migração internacional; Chile; Segurança, Doutrina da Segurança Nacional; governabilidade migratória.

$* * *$

\section{Introducción}

La migración internacional se ha instalado definitivamente en la opinión pública chilena en los años recientes, de la mano de un incremento de la llegada de migrantes, sobre todo en el último decenio ${ }^{2}$. Vista desde el presente, la afirmación parece una obviedad, pero tras escuchar de funcionarios y representantes del Estado, por al menos una década, que uno de los obstáculos más importantes para la modificación de la principal norma que rige este asunto en el país - el decreto ley 1.094, gestado en el período inicial de la dictadura del General Pinochet - era que el tema no estaba "en agenda”, esta constatación se torna significativa. Aunque opinión pública y agenda pública nos son nociones equiparables, generalmente la instalación de un tema en la primera suele implicar su inclusión en la segunda. De ahí a que exista la voluntad política para materializar esa inclusión en la gestación de una política, o su modificación, hay otro gran trecho, que al menos en este caso específico parece ser bastante amplio, como lo ponen en evidencia las varias postergaciones de la presentación de un nuevo proyecto de ley durante la administración actual, aún a pesar de una clara voluntad sectorial —del DEM puntualmente_-, y de un proceso bastante amplio de elaboración de ese texto legal, que contempló la participación (al menos formal) de representantes de la academia y de las organizaciones de la sociedad civil vinculadas al tema.

En este contexto, se han presentado durante el último año algunas iniciativas de modificación parcial del marco regulatorio actual, lideradas sobre todo por legisladores que representan a las regiones del norte del país, especialmente Antofagasta ${ }^{3}$. Tanto los contenidos de esas propuestas, como las expresiones públicas de estos legisladores en ese escenario, 
revelan una tendencia preocupante hacia dos componentes principales de un enfoque de seguridad de los procesos migratorios: el aumento de los mecanismos de control para el ingreso y el incremento de las ocasiones y la “efectividad” de las expulsiones. Por una parte, la diputada Paulina Núñez (RN) presentó en noviembre de 2015 un proyecto que propone modificar el artículo 34 de la Ley 18.216, que establece penas sustitutivas a las penas privativas de libertad. El proyecto establece que si el condenado por un delito simple es un extranjero que reside “de manera ilegal” en el país, el juez podrá sustituir la pena por la expulsión del territorio nacional, ya sea de oficio o a petición de cualquiera de los intervinientes. En octubre la diputada, junto al senador Alejandro Guillier(independiente), habían presentado ante el jefe del DEM algunas propuestas para la modificación del DL 1.094, que contemplaban entre otras cosas la necesidad de postular a un permiso de residencia temporal en la embajada o consulado del país de origen, antes de migrar, además de establecer tipos penales especiales y crear mecanismos más expeditos para la expulsión de los condenados por sentencia judicial o por decisión administrativa. El diputado Marcos Espinosa (PRSD), por su parte, acompañado por varios legisladores, presentó en diciembre de 2015 una moción que solicita la introducción de indicaciones a la actual Ley de Extranjería, con el propósito que se amplíen los delitos por los que se puede restringir la entrada de inmigrantes al país y se homologuen los antecedentes de los países de origen y destino ${ }^{4}$.

En principio, la coexistencia de estos dos impulsos, es decir, por una parte, el de modificación del DL 1.094 con un proyecto que se sustentaría en un enfoque de derechos humanos, y consideraría especialmente el derecho a migrar, y por la otra, estas iniciativas tendientes a limitar la movilidad y potenciar una práctica estatal arbitraria y violenta como es la de la expulsión (Domenech 2015) ${ }^{5}$, parece contradictoria. Pero un análisis detenido del anteproyecto de ley que se pretende presentar muestra que la contradicción es aparente, en la medida que permite advertir la continuidad de un nexo entre migración y seguridad que ha sido persistente en el modo que el Estado chileno ha pensado migración al menos durante las últimas cuatro décadas ${ }^{6}$.

En este marco, la propuesta que ordena el derrotero de este artículo es analizar una arista del abordaje estatal de la migración internacional en Chile entre 1975 y $2014^{7}$ : aquella que se cristaliza en un conjunto de documentos seleccionados que se consideran condensaciones claras del pensamiento de Estado sobre este proceso social en ese lapso: el propio decreto ley 1.094, de 1975 y aún vigente (y los informes que circularon durante su proceso de gestación); el proyecto $\mathrm{N}^{\circ} 2891$ de modificación de esa norma, de 1993, presentado bajo la presidencia de Patricio Aylwin (1990-1994); el instructivo presidencial sobre Política Nacional Migratoria de 2008, elaborado durante el primer período presidencial de Michelle Bachelet (20062010) en el marco de los intentos de modificación del DL 1.094, y el Proyecto de Ley de Migración y Extranjería No 8970-06, presentado en 2013 por el gobierno de Sebastián Piñera (2010-2014), que aún se encuentra en trámite parlamentario, aunque estancado, y sin haber alcanzado la instancia de debate en sala. 
A través de una aproximación inductiva, abordada desde la metodología del análisis crítico del discurso, el artículo se propone mostrar la persistencia de la idea de seguridad vinculada a las migraciones en estas cristalizaciones normativas, idea que actúa como hilo conductor de este modo de pensar la migración internacional del Estado chileno en las últimas cuatro décadas, pero también la forma en que este significante se ha ido transformando a lo largo de este período, transitando desde el paradigma de la Doctrina de la Seguridad Nacional al de la gobernabilidad migratoria (Domenech 2011; 2013). Sin desconocer los desarrollos teóricos y los debates conceptuales que se han producido en el campo de estudio de la seguridad y las migraciones, este trabajo tiene un énfasis empírico deliberado, en la medida que pretende ser un aporte a la discusión que se produce actualmente en Chile en torno al proyecto de modificación de la normativa migratoria actualmente vigente.

\section{Seguridad nacional: el migrante como potencial enemigo interno ${ }^{8}$}

El DL 1.094 se elaboró y aprobó durante lo que se considera el período fundacional de la dictadura del General Augusto Pinochet (Ansaldi y Giordano 2012), puntualmente en 1975. Se trata de una norma claramente signada por el conjunto de principios que constituyeron el sustento ideológico de esta y otras dictaduras institucionales del Cono Sur, la Doctrina de la Seguridad Nacional, con el claro propósito implícito de impedir el ingreso de "agitadores" - la acción indirecta del comunismo - que pudieran atentar contra el "orden interno". Como una prueba más del carácter pactado de la democracia chilena —y de la naturaleza institucional de su dictadura-, esta norma sigue vigente a cuatro décadas de su aprobación, a pesar de algunos intentos de modificación que hasta ahora no han prosperada.

La DSN consiste en una sistematización de teorías y experiencias relacionadas con la geopolítica, adoptada al concluir la Segunda Guerra Mundial, e inscripta en el marco de la Guerra Fría (Velásquez Rivera 2002). La versión más elaborada de esta doctrina que se conoció en América Latina desde la década de 1960 provendría de teorías geopolíticas, antimarxistas y de la extrema derecha del pensamiento social católico, de organizaciones como el Opus Dei, plasmadas en la experiencia de los militares franceses en las guerras coloniales de Indochina y Argelia. Con la derrota de los franceses en esas experiencias, la posta de la formación militar en esta doctrina la tomó Estados Unidos, que comenzaba su intervención militar en Vietnam y se enfrentaba a los desafíos que le suponía la Revolución Cubana (Moreira Alves s/f; Ansaldi 2004; Ansaldi y Giordano 2012). Ese “traspaso” también supuso algunos cambios en este marco ideológico.

La bipolaridad mundial que se había conformado tras la Segunda Guerra Mundial, sostenían los teóricos estadounidenses de la DSN, habría llevado al reemplazo de las guerras convencionales por las guerras ideoló- 
gicas dentro de las fronteras de cada país, guerras entre el "mundo libre occidental y cristiano" y el "totalitarismo comunista ateo", en las que se combatía en todos los frentes -militar, político, económico, social, cultural e ideológico (Ansaldi 2004; Ansaldi y Giordano 2012).

La geopolítica, que tiene un rol central en la conformación y definición de esta doctrina, irrumpió en la fase imperialista del capitalismo en expansión, como una forma de justificación de ese expansionismo. Esta perspectiva se sustenta en la categoría positivista del "espacio vital” y en una explicación organicista de la sociedad (Velásquez Rivera 2002: 12). Este trasfondo ideológico aparece con mucha claridad y profusión en un texto que reúne y sistematiza apuntes de clase de la cátedra de Geografía Militar, dictada por Pinochet en diversos institutos militares nacionales en los años previos al golpe de Estado, y que se titula Geopolítica de Chile (Pinochet Ugarte 1983).

Es este contexto descrito brevemente el que permite entender la gestación del DL 1.094 de 1975 que "establece normas sobre extranjeros en Chile”. En primer lugar, llama la atención la temprana preocupación por legislar sobre la materia, considerando que Chile no era un gran receptor de flujos migratorios por entonces, y que tampoco era probable que comenzara a serlo, en el marco de un contexto dictatorial ${ }^{9}$. De hecho, la comisión que se encargó de elaborar el primer borrador del decreto comenzó a sesionar ya en julio de 1974, es decir, durante lo que se ha llamado la fase fundacional de la dictadura, entre 1974 y 1980 (Ansaldi y Giordano 2012). La DSN, que sirve de sustento a los principios de esta norma, permite entender esta preocupación: la preocupación por la seguridad nacional, entendida desde este trasfondo, es prioritaria desde los comienzos del régimen, aparece ya en su "Declaración de Principios”. De hecho, el elemento central del documento “Objetivo Nacional del Gobierno de Chile”, dado a conocer en 1975, gira en torno a la seguridad nacional, condicionada por el liberalismo económico (Arriagada 1998), otro rasgo que aparece con mucha claridad en la norma migratoria.

El énfasis de la aplicación de la DSN en América Latina estuvo puesto en la seguridad interna, ante la preocupación por el crecimiento de los movimientos sociales de clase obrera. En ese escenario, la supuesta amenaza a la seguridad nacional provenía de la subversión interna y la guerra revolucionaria: el enemigo interno, un concepto esencial cuando el énfasis se desplaza desde la idea de frontera territorial a la de frontera ideológica (Moreira Alves s/f). Sin embargo, el resguardo de la frontera territorial como espacio por el que podían ingresar "agitadores” que podían amenazar este orden interno - la frontera territorial hecha frontera ideológica - parece haber sido una preocupación importante, que explica esta temprana intención de control. En definitiva, en el marco de la idea de la guerra total que guiaba la DSN, el enemigo era interno y externo a la vez (Arriagada 1998).

La lógica que anima este sustrato ideológico aparece con claridad en algunas de las razones de la necesidad de elaborar esta norma que se seña- 
lan en uno de los documentos que circuló al inicio de su proceso de redacción: “a) Cautelar el interés nacional y la Seguridad Interior del Estado; (...) i) Cubrir la actual falencia de medios logísticos de los organismos públicos de extranjería, especialmente de los Servicios contralores para hacer más eficaz su labor de control policial directo, preventivo y represivo, así como de ingreso y egreso"10. El mismo informe se cierra sosteniendo que: "La Comisión elaboró y redactó este proyecto de Decreto Ley considerando principalmente, la necesidad que existe de mejorar las actuales disposiciones legales y la conveniencia de preservar la seguridad nacional”11.

Esta lógica de la seguridad nacional que informa el decreto aparece explícitamente al comienzo del articulado. Ya en el artículo $3^{\circ}$ de la versión original (actualmente el $2^{\circ}$ ) se establece que: “El Supremo Gobierno podrá, por razones de interés o seguridad nacional, disponer que se impida el ingreso al país de determinadas personas" ${ }^{12}$. La evidente arbitrariedad contenida en esta disposición es además un rasgo característico de la aplicación de esta doctrina: “O próprio Estado de Segurança Nacional -e freqüentemente seus setores mais íntimamente ligados ao Aparato Repressivo- determina em última instância quem é o “inimigo interno” do pais, e que atividades de oposição constituem "antagonismos” ou "pressões" (Moreira Alves s/f: 8).

La relevancia del aparato policial del Estado de Seguridad Nacional que aparece en la cita de Moreira Alves, uno de los tres pilares de la dictadura chilena según el análisis de Arriagada (1998) — los otros dos habrían sido el poder político “incontrarrestable” en manos del Comandante en Jefe del Ejército y el triunfo de los Chicago boys para dirigir el rumbo económico del país-, estuvo presente en el proceso de gestación de esta norma. En una de las observaciones que remitió el Ministerio del Interior a la Comisión de Asesoría y Coordinación Jurídica, a cargo de la coordinación del proceso, se sostenía que el artículo $101^{\circ}$ se había incorporado "en atención a los requerimientos de los representantes del Ministerio de Defensa y DINA [Dirección de Inteligencia Nacional, policía secreta del régimen y con facultades casi ilimitadas (Gazmuri 2003), reemplazada en 1977 por la CNI Central Nacional de Informaciones-], los cuales hicieron primar el factor de seguridad sobre el particular"13 . Ese artículo $101^{\circ}$ establecía que: "En situaciones de emergencia y cuando los intereses nacionales lo exijan, por decreto supremo fundado del Ministerio de Defensa Nacional, se podrá dictar algunas de las siguientes normas especiales de control de extranjeros, cualquiera que sea su condición legal de residencia: a) Arresto hasta por 30 días; b) Residencia obligada en un punto habitado del país; c) Prohibición de residir en uno o más puntos determinados del territorio nacional; d) Prohibición de desempeñar determinadas actividades; y e) Sujeción a la vigilancia y control de la autoridad policial”. El artículo $4^{\circ}$, por su parte, establecía además que las vías de acceso al país habilitadas podrían cerrarse a las personas en forma temporal o indefinida (actualmente artículo $3^{\circ}$ ).

El artículo $19^{\circ}$ (actualmente el $15^{\circ}$ ) establecía que podría prohibirse el ingreso, entre otras categorías, de "[l] os [extranjeros] que propaguen o 
fomenten de palabra o por escrito o por cualquier otro medio, doctrinas que tiendan a destruir o alterar por la violencia, el orden social del país o su sistema de gobierno, los que estén sindicados o tengan reputación de ser agitadores o activistas de tales doctrinas $\mathrm{y}$, en general, los que ejecuten hechos que las leyes chilenas califiquen de delito contra la seguridad exterior, la soberanía nacional, la seguridad interior o el orden público del país y los que realicen actos contrarios a los intereses de Chile o constituyan un peligro para el Estado" (...), "los que ejecuten actos contrarios a la moral o a las buenas costumbres", y "[l] os que por razones de conveniencia o utilidad para el país no se hagan dignos del permiso solicitado”.

Otra disposición coherente con el propósito germinal de la norma, es decir, el control del ingreso de potenciales enemigos internos de la seguridad nacional, aparece en la figura de la expulsión, cuya decisión finalmente quedó en manos de un decreto supremo fundado, excepto en el caso de los turistas - la forma de ingreso más común al país-, para quienes podía disponerse por resolución administrativa exenta del trámite de toma de razón (artículo $95^{\circ}$ en la versión original de 1975, actualmente artículo 84, con modificaciones). La redacción de este artículo fue objeto de debate entre el Ministerio del Interior y la Comisión Asesora durante el proceso de gestación de la norma, que solicitaba la necesidad de un recurso judicial para la expulsión. Obviamente la opción que terminó primando fue aquella que “agilizaba” los procesos de expulsión y los tornaba más arbitrarios.

Ahora bien, esta centralidad de la idea de seguridad ligada a la migración, asociada en este momento al entramado ideológico de la DSN, y enmarcada a su vez en el escenario de la Guerra Fría, se articula en la norma con otras disposiciones y regulaciones que ponen en evidencia la matriz biopolítica que le subyace ${ }^{14}$. La figura de la migración como una variable de los cálculos estatales sobre su población y su economía atraviesa el texto del DL 1.094 y su reglamento, articulándose con la condensación de significaciones en torno a la asociación seguridad-enemigo interno: la norma establece que podrá prohibirse el ingreso al país, entre otras categorías, de "[l]os que no tengan o no puedan ejercer profesión u oficio, o carezcan de recursos que les permitan vivir en Chile sin constituir carga social” (artículo 15, inciso 4), y que "[l]as atribuciones que correspondan al Ministerio del Interior, para el otorgamiento de visaciones, para las prórrogas de las mismas y para la concesión de la permanencia definitiva serán ejercidas discrecionalmente por éste, atendiéndose en especial a la conveniencia o utilidad que reporte al país su concesión y a la reciprocidad internacional, previo informe de la Dirección General de Investigaciones” (artículo 13). Es decir, emerge ya tempranamente la mirada costo-beneficio de los procesos migratorios, que luego adquiere centralidad en el paradigma de la gobernabilidad migratoria.

El reglamento del decreto elaborado bajo la dictadura de Pinochet ( No 597, de 1984) condensaba una clara preocupación por que el extranjero demostrara su capacidad económica (es decir, ni siquiera su capacidad de "ocuparse de algo", de no "permanecer ocioso", sino de no significar un 
gasto para el Estado). Para solicitar visación, por ejemplo, era preciso acreditar solvencia - y salvo algunas excepciones, como la de las visas otorgadas a los niños y adolescentes por su matriculación en un establecimiento escolar, sigue siéndolo. Una de las posibilidades de prohibición de ingreso reside, como se dijo, en el hecho que el extranjero no tenga profesión, oficio o recursos que le permitan no representar una "carga social” para el Estado. En el caso de la visación de estudiante, el extranjero que tuviera este estatus residencial y quisiera prorrogarlo debía "acreditar, en caso de no ser becado, la percepción periódica y regular de medios económicos para el sustento” (artículo 45). Algo similar ocurría respecto del turista, para quien se establecía que debía acreditar, cuando la autoridad policial de frontera lo estimara necesario, "que tiene los medios económicos suficientes para subsistir durante su permanencia en el país” (artículo 87) —un resquicio del que los funcionarios de la Policía de Investigaciones (PDI), a cargo del control de las fronteras, se siguen valiendo discrecionalmente hasta la actualidad $^{15}$. Este sesgo también se evidencia en varios de los casos que se consideraban "útiles y ventajosos” para el otorgamiento de visas de residentes temporarios: "Empresarios, inversionistas, comerciantes, rentistas y en general personas de negocios...” (artículo 50, inciso a); y “[c]ientíficos, investigadores, académicos, conferencistas, profesores, profesionales, técnicos, expertos, cuya admisión sea requerida por personas jurídicas nacionales o patrocinadas por Organismos Internacionales reconocidos por el Gobierno de la República o que viajen por más de 90 días...” (artículo 50, inciso b).

Ciertamente el hecho que el contexto de aplicación del decreto que aún rige la migración internacional en Chile ya no sea el dictatorial -en estrecha vinculación con el marco normativo complementario que se ha ido conformando durante el período de los gobiernos democráticos - supuso progresivamente cambios en la forma en que la norma opera, pero lo cierto es que la persistencia del trasfondo restrictivo y persecutor de su texto sigue teniendo consecuencias que hacen urgente la modificación de este régimen legal. Más allá de esta demanda ineludible, también es cierto que ese concepto de seguridad que sustentó su elaboración, esa seguridad entendida como la seguridad del propio Estado frente a enemigos que se consideran elementos externos a ese Estado, se ha ido transformando durante el transcurso de los gobiernos democráticos que siguieron a la dictadura de Pinochet. Esa transformación en la persistencia es el objeto de análisis del próximo apartado.

\section{Persistencias y transformaciones: seguridad, utilidad y derechos}

\section{La seguridad como componente del nexo entre migración y desarrollo}

El siguiente texto que se considera una cristalización significativa del pensamiento del Estado chileno respecto de la migración internacional 
es el Proyecto de Ley sobre Migraciones $N^{\circ}$ 2.891, presentado en noviembre de 1993, es decir, durante los primeros años de los gobiernos democráticos tras la dictadura de Pinochet. El proyecto, archivado finalmente en julio de 1997, fue elaborado durante la gestión de Patricio Aylwin (19901994), que encabezaría el primer proceso de actualización de la legislación migratoria tras el régimen dictatorial. La presentación del proyecto habría sido "el primer paso en la modernización de una ley que para esa época, no se encontraba preparada para responder a los crecientes desafíos que Chile enfrentaría en relación con la movilidad de las personas” (DEM 2007).

El texto es importante dentro de este corpus seleccionado en la medida que supone un punto de transición entre la relación entre migración y seguridad nacional versus enemigo interno, anclada en el paradigma de la DSN, hacia el nexo entre seguridad y migración que se construye desde el paradigma de la gobernabilidad migratoria, centrado en la equiparación de las ideas de migración regulada-migración segura, en el marco de una vinculación entre migración y desarrollo y del recurso a la legitimación del discurso de los derechos humanos - lo que se aborda detalladamente en el próximo apartado- - En este texto en particular, que puede considerarse el eslabón entre estos dos enfoques, comienza a perfilarse este vínculo entre la migración internacional y el desarrollo nacional, que adquiere un carácter definitorio en este caso, y también el énfasis en la necesidad de "regular" las migraciones, un constructo distintivo de la gubernamentalidad liberal, en la que el énfasis deja de estar puesto en la prohibición para trasladarse al control como mecanismo de contrapeso de las "libertades".

En este texto, como en los que se analizan en los próximos apartados, la seguridad no aparece como un eje estructurador explícito, sin embargo, atraviesa todo el entramado discursivo emergiendo como uno de sus puntos nodales, a veces emergiendo como enunciado (como acontecimiento discursivo), y otras como trasfondo en los mecanismos que van definiendo el trámite migratorio, entendido como "un entramado de reglas, procedimientos, prácticas, decisiones, en fin, rutinas burocráticas, a través del cual se decide sobre la legalidad de los migrantes” (Cerianiet al. 2009:172).

En el proyecto de ley 2.891 la migración se transforma en un potencial agente de desarrollo que requiere ser regulado para su materialización efectiva: "La política nacional migratoria estará destinada a promover la inserción y reinserción de los nacionales ${ }^{16}$ y extranjeros necesarios para el país, cualitativa y cuantitativamente, así como a orientar, cuando sea del caso, su asentamiento y localización geográfica y por ramas de actividad, con el objeto de lograr el desarrollo creciente, armónico, pleno y permanente de la República” (artículo 4). En el caso de la inmigración, en su regulación debiesen considerarse las "necesidades demográficas, sociales, económicas y culturales del país, cuya satisfacción sea de interés para la nación en su conjunto” (artículo 2).

Desde este enfoque, el proyecto considera explícitamente la posibilidad de incentivar una migración planificada, distinguiendo con este fin 
entre la inmigración espontánea y la programada ${ }^{17}$. Esta última se define como "aquella que obedece a un proyecto previo, aprobado por el Gobierno Chileno, tendiente a procurar la inserción de extranjeros, en áreas geográficas o actividades preestablecidas” (artículo 12), y puede demandar asistencia económica del gobierno chileno para el traslado internacional e interno del inmigrante, además de subsidios especiales para su instalación e inserción. Incluso se contemplan franquicias como un "elemento necesario para... incentivar o desincentivar la localización y movilidad de nacionales y extranjeros en Chile”. En esta línea de vinculación entre migración y desarrollo, se crean además tipologías específicas de migrantes, que son de particular interés y tratamiento: el migrante con capital, el rentista y el migrante por temporada, una figura que emerge ya en ese momento y que ha persistido como un tópico de importancia hasta la actualidad, en estrecha vinculación con algunas actividades económicas relevantes para el país — principalmente, el levantamiento de ciertas cosechas destinadas a la exportación.

La preocupación por que la migración que llegue sea funcional a los intereses del país, y no represente un costo para el Estado — esta lógica del costo-beneficio, que adquirirá un carácter central en el paradigma de la gobernabilidad migratoria - aparece de manera profusa en el texto: "Considérase Inmigrante, al extranjero que viene a instalarse en Chile a fin de desarrollar por cuenta propia o en relación de dependencia, cualquier clase de actividad que las autoridades competentes consideren de interés para el país y que le permita al solicitante y sus familiares, vivir digna y congruamente, sin constituir por consiguiente una carga social y económica para el Estado Chileno" (artículo 29). En este sentido, es importante determinar con claridad las características que deberá tener el migrante que llegue al país (o al que se le permita llegar). También hay un claro enfoque asimilacionista, varias veces explicitado, en relación a la dimensión sociocultural del proceso migratorio, que ha persistido incluso hasta el anteproyecto de ley que se está discutiendo actualmente: en el proyecto se consideran "aspectos como la necesidad de una normal y progresiva inserción programada y congruente con los objetivos trazados al incorporar extranjeros, a fin de evitar el riesgo de que en el mediano y largo plazo, se tengan colonias cerradas o con bajo interés de asimilación a la nación chilena”.

En relación a la consideración explícita de la cuestión de la seguridad, persiste la idea de evitar aquella migración que pudiese representar una alteración del orden público o un compromiso de la soberanía nacional o la seguridad exterior del Estado - tanto como causal de negación del ingreso como de revocación del permiso-, pero se suma también, en relación al contexto en el que se gesta el proyecto, una noción de la seguridad ligada a prácticas de delincuencia internacional como "el comercio, consumo o tráfico ilícito de drogas, armas o personas o el contrabando”, de las que el migrante internacional podría ser parte. Aparece también la imposibilidad de admitir a "los condenados o procesados por delito o cuasidelito", además de los prófugos de la justicia, los expulsados y los deportados con prohibición de reingreso al país. Estos causales de no admisión, junto a la realización de "actos contrarios a la moral, a las buenas costumbres o a los 
intereses de Chile”, el padecimiento de enfermedades infecciosas, contagiosas o transmisibles "que hayan sido calificadas como un riesgo para la salud pública", de "alienación o insuficiencia mental que altere [los] estados de conducta”, y la carencia de oficio, profesión o recursos (artículo 104), corresponderían según el texto a "lo que la gran mayoría de las legislaciones migratorias establece como protección respecto de los extranjeros indeseables". También puede rechazarse el ingreso cuando el migrante registrase "antecedentes en Investigaciones o Carabineros de Chile, procedentes de sus propios registros y archivos o de los registros de la Organización Internacional de Policía Criminal (INTERPOL) que no hagan aconsejable su ingreso" (artículo 202).

Con los nuevos rasgos que le imprime esta concepción de la migración como potencial recurso para el desarrollo del país, persiste un estrecho vínculo con la seguridad en el pensamiento de Estado sobre la migración. Esta persistencia revela sus conexiones con la matriz que primó en el período anterior (la DSN), mientras que las nociones de desarrollo y regulación anticipan el perfil del paradigma que se está gestando. Sin embargo, para su plena emergencia falta en este texto un elemento decisivo, el de los derechos humanos, que está completamente ausente. Será en la próxima cristalización que la globalización del enfoque de derechos (Abramovich 2006) encuentre su cauce.

\section{La migración segura: regularidad, beneficios mutuos y derechos}

El texto normativo que se considera emblemático de la cristalización de la perspectiva de la gobernabilidad migratoria en el modo en que el Estado chileno ha pensado la migración internacional es un instructivo ministerial que se aprobó en 2008, durante el anterior gobierno de Michelle Bachelet ${ }^{18}$, y que en ese momento se concibió como un prolegómeno de la aprobación de una nueva ley migratoria que finalmente nunca se concretó. Aunque este instructivo es el que se considera como texto-hito, por la relevancia que ha mantenido hasta la actualidad, esta mirada estatal sobre las migraciones internacionales aparece igualmente en varios documentos gubernamentales y declaraciones públicas de los funcionarios de gobierno por aquella época ${ }^{19}$.

La perspectiva de la gobernabilidad migratoria, impulsada por organismos internacionales como la OIM y la propia Organización de las Naciones Unidas (ONU), a través de diversas agencias, se vincula al propósito de instauración de un régimen global de control migratorio. Para ello, se ha instituido la idea que existe una estrecha relación entre la protección de los derechos humanos de los migrantes y la administración "efectiva" de los flujos migratorios, es decir, una gestión que permita lograr que estos desplazamientos de personas sean ordenados, predecibles y "aceptables" esto es, útiles a los intereses del país de destino-, y por lo tanto manejables. Según este enfoque, la regularidad de estos flujos — es decir, la circulación de los migrantes por los canales establecidos por los Estadospotencia las ganancias y aminora los costos de la migración, y asegura que 
estos procesos generen un beneficio muto (en términos de desarrollo): tanto para los migrantes y sus países de origen como para los países receptores. Se trata en definitiva de lo que Domenech (2011) ha dado en llamar las "políticas de control con rostro humano", es decir, el "universo de ideas y prácticas que, enmarcadas en el discurso de los derechos humanos como fuente de legitimación, persiguen la misma finalidad que las políticas más abiertamente restrictivas, prometiendo ser más eficaces en la consecución de su objetivo: controlar los flujos migratorios internacionales”. Y los dispositivos de seguridad son un elemento vital en esta regulación. La labor de incidencia política de estas agencias internacionales se ha materializado en varias reformas de las legislaciones migratorias de países de la región la de Argentina por ejemplo-, y Chile ha realizado una apropiación institucional de esta incidencia. De hecho, en varios de los documentos oficiales de la época referidos al tema se citan explícitamente recomendaciones de la OIM.

Esta perspectiva se articula en este texto normativo con una construcción de significaciones en torno a la idea de seguridad que, aunque manteniendo algunos elementos conectivos con las anteriores, experimenta una transformación relevante: la seguridad se introyecta ahora al propio proceso migratorio, y por ende al migrante: se trata de fomentar una migración segura. Esta noción de migración segura tiene un perfil doble: supone tanto proteger al propio migrante de acciones que puedan atentar contra su seguridad —-"[l]a migración debe producirse en condiciones en que la vida del inmigrante no corra peligro. Para ello, se promoverán acciones que permitan prevenir y sancionar tanto el tráfico ilícito de migrantes, como la trata de personas"- , como proteger a la sociedad nacional de los peligros que algunos migrantes puedan significar: "cuando efectos negativos derivados del fenómeno migratorio pudiesen generar tensiones internas o crisis a nivel bilateral o internacional, el Estado podrá cautelar a través del ordenamiento jurídico, los riesgos a la seguridad que pudieran asociarse a los fenómenos migratorios. Se generarán medidas que permitan restringir el acceso al país a aquellas personas que en razón de sus antecedentes policiales o judiciales, constituyan un peligro para la sociedad”. Este elemento, que había comenzado a emerger en el texto normativo anterior que consideramos en este análisis, se consolida ahora, pero además se vincula de manera directa con la importancia que se asigna a la regularidad migratoria.

Esta construcción significativa en torno a la relación migración-seguridad se hacía manifiesta también, como decía, en algunas declaraciones a medios masivos de comunicación de funcionarios del gobierno encargados de estos temas, en el marco de los anuncios de modificación de la ley. Felipe Harboe por ejemplo, entonces subsecretario del Interior, decía al diario nacional El Mercurio en febrero de 2007 que "Chile es un país abierto, pero debe velar por su seguridad, por lo que se quiere regularizar a los extranjeros ilegales”. Estas declaraciones se enmarcaban en el proceso de regularización migratoria realizado ese año ${ }^{20}$. El ex subsecretario anunciaba que se estaba elaborando un proyecto de ley para crear una nueva política migratoria, que podría ser enviado en el curso de ese año para su tramita- 
ción, y explicaba que esa futura norma debía “compatibilizar que Chile es un país abierto a la comunidad internacional con su deber de velar por su seguridad interior". Además, afirmaba que eran bienvenidos "todos aquellos que quieran incorporarse a nuestra sociedad de manera regular y a trabajar lícitamente, que es la gran mayoría, pero aquellos que quieren hacer de la actividad delictual su forma de vida, tenemos mecanismos destinados a evitar eso o a sancionar duramente cuando sean detectados". La tramitación y promulgación de la ley sobre trata de personas y tráfico de migrantes durante esta gestión de gobierno es parte de esta lógica. Esta vinculación específica entre migración y seguridad a la que aludimos puede advertirse también en las medidas que anunciaba el funcionario que se tomarían para prevenir el ingreso de "extranjeros ilegales" mientras se tramitaba la ley: "fortalecer los pasos fronterizos, implantar controles más estrictos en pasos no habilitados y establecer sanciones a aquellos que ingresan irregularmente al país e inician actividades ilícitas”.

El análisis detallado de la comunicación presidencial de 2008, que fijaba pautas y acciones futuras para una política migratoria, revela la presencia articulada a esta noción de seguridad en torno a la migración internacional con algunas de las ideas-fuerza de la perspectiva de la gobernabilidad migratoria, que hemos estado describiendo: la preocupación por la regularidad y gestión ordenada de los flujos migratorios; la relación migracióndesarrollo, en la medida en que se logre "encauzar" apropiadamente estos flujos; la evaluación costo-beneficio que hace el Estado para determinar las regulaciones que finalmente incidirán en quiénes tienen más dificultades para ingresar al país, y la apelación al discurso de los derechos humanos como herramienta legitimadora.

En el texto oficial se sostiene que el debate internacional sobre la migración se ha centrado en el reconocimiento de los derechos humanos con independencia de la situación migratoria de la persona, y que se ha reconocido el estrecho vínculo de la migración con el desarrollo, "que puede contribuir de manera fundamental al mejoramiento de las condiciones de vida tanto en los países de origen como de destino". Definiendo a Chile como "un país adecuadamente abierto a las migraciones", el instructivo sostiene que "se impulsarán medidas tendientes a fortalecer la gobernabilidad migratoria”, para lo que el Estado asumirá un rol activo frente al fenómeno migratorio, "a fin de regularlo, cuantificarlo y conducirlo hacia la integración del colectivo migrante”.

La matriz biopolítica de la gubernamentalidad liberal es en este punto una herramienta conceptual útil para el análisis: el flujo de migrantes aparece concebido como un hecho probable que es necesario prever, dimensionar y gestionar para el beneficio del Estado, junto al recurso legitimador de los derechos humanos y la idea de integración.

Otro de los ejes de la acción gubernamental frente al fenómeno de la migración que se detallan en esta comunicación presidencial es, como decíamos, la "capacidad de regulación y administración”: "El derecho interna- 
cional sobre los derechos humanos reconoce a los Estados el derecho y el deber de desarrollar marcos jurídicos sobre migración, para la protección de la seguridad de su población, y para conseguir crecientes niveles de bienestar. En este contexto, el Estado de Chile no renunciará a su rol de orientar el acceso a la residencia, cuando ello sea necesario en beneficio del Estado y de las personas que habitan su territorio". Es decir, la libertad de movimiento está condicionada a las consideraciones de seguridad. Esta relación compleja entre libertad y seguridad-control, propia de la gubernamentalidad liberal, encuentra su correlato en la gobernabilidad migratoria ${ }^{21}$.

La otra gran arista de la gobernabilidad migratoria que se advierte en el texto del instructivo presidencial de 2008 es el recurso al reconocimiento de los derechos humanos de los migrantes. En ese marco, se reconocen el derecho a la residencia y la libertad de circulación ("salvo siempre el perjuicio de terceros”); a la libertad de pensamiento y conciencia; al acceso a la justicia; a la integración y protección social, a partir del acceso a la educación, la salud y el trabajo; a los derechos laborales, a la no discriminación, entre los más relevantes.

Es preciso señalar que este reconocimiento de derechos había comenzado a materializarse ya en el gobierno anterior, presidido por Ricardo Lagos (2000-2006), y siguió ampliándose durante el primero gobierno de Michelle Bachelet. En 2005 Chile ratificó la Convención Internacional sobre la protección de los derechos de todos los trabajadores migratorios y de sus familiares, de las Naciones Unidas. Además, desde 2003 en adelante aunque hay algunas medidas previas, pero de alcance limitado- se han firmado convenios específicos para asegurar el derecho a la educación de los niños y adolescentes migrantes (Oficio Ordinario $N^{\circ}$ 07/1008-1531 del Ministerio de Educación, de agosto de 2005, y resolución exenta $N^{\circ} 6.677$, de noviembre 2007, acordada entre el Ministerio del Interior y la Junta Nacional de Jardines Infantiles, JUNJI), a la salud en el caso de las mujeres embarazadas (Oficio circular $\mathrm{N}^{\circ} 1.179$, acordado entre el Ministerio del Interior y Seguridad Pública y el Ministerio de Salud), los niños (resolución exenta $N^{\circ} 1.914$ del Departamento de Extranjería y Migración, DEM, de 2008) y las situaciones de emergencia para los migrantes irregulares (Ordinario A14 N 3229 del Ministerio de Salud, de 2008), y a la protección de la infancia (Resolución Exenta $N^{\circ} 10.654$, entre el DEM y el Servicio Nacional de Menores, SENAME, de 2009) y de las mujeres migrantes y refugiadas ante la violencia intrafamiliar (Resolución Exenta $\mathrm{N}^{\circ}$ 80.388, entre el DEM y el Servicio Nacional de la Mujer, SERNAM, de 2009), entre otros. Sin embargo, siguen registrándose violaciones flagrantes de estos derechos, tal como lo han relatado diversas ONG que trabajan por y para los migrantes en el país, como el Servicio Jesuita a Migrantes o el INCAMI, en presentaciones en seminarios; como lo han recogido los servicios de clínicas jurídicas de migrantes que ofrecen algunas universidades, una de las cuales incluye con frecuencia un capítulo dedicado al tema en el informe sobre los derechos humanos en Chile que realiza anualmente (CDH-UDP 2006; 2007; 2008; 2010 y 2011). 
Pero más allá de esta concreción real o no de este reconocimiento, que excede los objetivos del artículo — acotado a un análisis documental, la apelación al discurso legitimador de los derechos humanos es parte de esta matriz biopolítica de la gubernamentalidad liberal que actúa como trasfondo de todas estas cristalizaciones textuales del pensamiento estatal chileno sobre la migración internacional. En efecto, desde esta perspectiva —la de la gubernamentalidad liberal—, la ideología jurídica de los derechos humanos constituye la forma originaria en la que la vida natural se inscribe en el orden jurídico-político del Estado-nación. Es decir, es precisamente de esta forma que el Estado-nación moderno gubernamentaliza la vida, se apropia de ella para administrarla. Esa nuda vida natural "pasa ahora al primer plano de la estructura del Estado y se convierte incluso en el fundamento terreno de su legitimidad y de su soberanía” (Agamben 2003: 323). Y lo hace a partir de una operación por la cual el Estado se apropia de la vida para luego arrogarse el poder de restituirla en la concesión de derechos, y en su supuesta protección. Es decir, los derechos humanos serían un mecanismo de intervención biopolítica.

\section{Coagulaciones del pasado: la seguridad nacional en clave utilitarista}

Es hacia el final del gobierno de Sebastián Piñera (2010-2014) que se presentó el proyecto de modificación del DL 1.094 que concitó mayor voluntad política de entre todos los intentos por cambiarlo que se han producido en el período que se analiza en este artículo, y que pretendo considerar como otro de los textos-hito respecto del pensamiento estatal chileno sobre la migración en las últimas cuatro décadas: el Proyecto № 8970-06, del 20 de mayo de 2013. Esta consideración obedece al hecho que, aunque en general el texto articula una mirada sobre la migración sustentada en los ejes principales de la perspectiva de la gobernabilidad migratoria —aunque con un énfasis utilitarista mucho más marcado- con una idea de seguridad semejante a la que se construyó en los textos previamente considerados, ligando la migración a fenómenos de delincuencia transnacional, en este caso irrumpen además en el texto la asociación con una preocupación internacional por el terrorismo, junto a ciertas coagulaciones en torno a la noción de seguridad que primó en el momento de gestación del DL 1.094, y que en principio podemos interpretar como "acontecimientos enunciativos" que remiten a la mirada sobre las migraciones que sigue presente en los enclaves autoritarios heredados de la dictadura que persisten en la sociedad chilena, obstaculizando su proceso de democratización.

Se trata de un texto jurídico que, al menos en el nivel de los mensajes explícitos, se sustentaría en el abordaje de la migración internacional desde la perspectiva de los derechos humanos ${ }^{22}$. Aunque más que a la preocupación por este asunto, la intención repentina y tardía de legislar sobre el tema de este gobierno ${ }^{23}$ se debió en buena medida a la presión de ciertos sectores empresariales, concretamente el dedicado a la exportación de productos agrícolas, por la necesidad de mano de obra temporal y más barata para labores no calificadas, y que remite a esta dimensión utilitarista de la circulación de la población que prima en la perspectiva de la gobernabilidad 
migratoria. Ciertos aspectos del proyecto de ley son muy evidentes en este sentido, por ejemplo, cuando se señalan las falencias del DL 1.094 que sustentan la necesidad de modificar "la legislación migratoria más antigua de Sudamérica”, se sostiene que: “El actual tope que establece el Código del Trabajo de 15\% de trabajadores extranjeros en las empresas no exceptúa a los trabajadores de temporada, pese a la marcada estacionalidad de ciertas labores como la cosecha agrícola, las que pueden requerir picos máximos de oferta laboral en periodos de tiempo muy específicos”. Para ello, se propone modificar esta restricción, y además se crea una categoría migratoria ad hoc. Es decir, el migrante interesa en la medida en que resulte útil, y siempre que se marche cuando deje de serlo.

Se trata en general de una propuesta normativa restrictiva y controladora, con un importante énfasis en las cuestiones de seguridad, y que solo pretende flexibilizar la entrada de ciertos tipos de migrantes, básicamente, aquellos trabajadores de temporada que se necesitan en algunos sectores de la economía, los profesionales y académicos altamente calificados y las personas de negocios que vienen a invertir al país, en definitiva, como se sostiene en el texto del proyecto: "La propuesta configura un mecanismo de formulación periódica de política migratoria, cuya principal materialización concreta es la definición de las subcategorías de residencia temporal.Dicho instrumento será el llamado a definir el grado de permeabilidad de nuestras fronteras, en función de la realidad económica y social reinante”. El papel central de la seguridad en el texto — mucho más significativo que en los dos anteriores - tiene nexos, por una parte, con la idea de la necesidad de proteger a la sociedad nacional de la delincuencia organizada transnacional y, por la otra, tiene claras líneas de continuidad con el discurso de la seguridad en que se fundó el decreto aún vigente, que se materializan incluso en el mantenimiento de párrafos casi textuales del DL 1.094. Por ejemplo, la primera causal de prohibición de ingreso de los extranjeros al país es que "posean antecedentes acreditados de conformidad a la legislación de sus respectivos países o registrados en la Organización Internacional de Policía Criminal, de pertenecer a movimientos o grupos terroristas o los que ejecuten o hayan ejecutado hechos que las leyes chilenas califiquen de delito contra la seguridad exterior, la soberanía nacional o la seguridad interior” (artículo 26, inciso 1).

La lógica de la seguridad y el control es un elemento principal, entre otros dos que ya he mencionado - la lógica del costo-beneficio de la migración, relacionada con la idea de la utilidad de los migrantes para el Estado receptor, y la apelación legitimadora a los derechos humanos-, en este proyecto de ley que pretendía modificar el DL 1.094. En el mensaje que fundamentó su presentación se sostiene que: “La migración regular permite también asegurar un adecuado control, manteniendo la seguridad nacional como un criterio informador de toda la legislación migratoria”. Además, en el artículo 16 del proyecto, entre los elementos que debería tener en cuenta el Presidente de la República para definir la Política Nacional de Migración y Extranjería, se sostiene que debería considerarse: “2. La política de seguridad interior y exterior del Estado, y el resguardo del orden público, espe- 
cialmente en lo referente a la prevención y represión del crimen organizado transnacional, el narcotráfico, el terrorismo y la trata de personas”. Además, los criterios de seguridad aparecen operando como razones para decidir el tiempo de estadía de los extranjeros en el país, o su misma permanencia; en el artículo 39 se afirma que: "Los titulares de permisos de permanencia transitoria podrán permanecer en el país hasta por 90 días. La Subsecretaría del Interior podrá limitar dicho plazo a un período menor, por razones de orden público o Seguridad Nacional, para lo cual deberá establecer criterios generales de aplicación”. Otro elemento interesante que abona esta idea tiene que ver con un argumento que aparecía en uno de los primeros borradores del proyecto que circuló extraoficialmente, pero que se "maquilló" en la versión definitiva. En aquella versión, una de las razones para el rechazo o la revocación definitiva de una residencia o permanencia era que los extranjeros: "Ejecuten actos que las leyes chilenas califiquen de delito contra la seguridad exterior, la soberanía nacional y la seguridad interior del país, y los que realicen actos contrarios a los intereses de Chile o constituyan un peligro para el Estado", como se advierte, una cita casi textual del DL 1.094. La redacción final es mucho más críptica, pero igual de arbitraria, pues se dice que podrán revocarse los permisos de residencia o permanencia de los extranjeros cuya "estadía en el país no se ajuste a los criterios establecidos en la Política Nacional de Migración” (artículo 79, inciso 6).

Otro elemento en el que aparece materializado con densidad discursiva esta asociación específica seguridad-migración es en la figura de la expulsión, que ha tomado un rol protagónico en el proyecto - y aquí la continuidad con el decreto vigente también es evidente. Se trata en todo caso de una estrategia que ha crecido notablemente a nivel mundial en el tratamiento de las migraciones internacionales,y del que nuestra región no ha estado ausente (Domenech 2015). Según se sostiene en los argumentos del proyecto de ley chileno, otra de las razones que demostraría las limitaciones del decreto actualmente vigente - y que justifican la necesidad de modificarlo- es la dificultad para la expulsión: "Pese a la lógica de seguridad nacional imperante, expulsar a un extranjero puede ser una empresa difícil, incluso aunque la culpabilidad del mismo esté debidamente probada, o si se constató que ingresó en forma clandestina. Se requiere la firma del Ministro del Interior y Seguridad Pública para el caso de los residentes, y no existe un mandato para la entrega de información por parte de los órganos de la Administración del Estado. Un régimen abierto a las oportunidades de la migración sólo cobra sentido si es posible expulsar, en forma expedita, a quienes se haya acreditado que atenten contra el bien común”. Y en ese sentido avanza el proyecto, haciendo más ágil el trámite de expulsión, entre otras cosas, cambiando la autoridad que suscribe los actos en que consta la orden de expulsión — del Ministro del Interior y Seguridad Pública al Subsecretario del Interior, quien a su vez podrá delegar esta facultad en otros funcionarios de menor rango- y cambiando la jerarquía del acto administrativo mediante el cual se dispone la expulsión -actualmente es por Decreto Supremo del Ministro del Interior y Seguridad Pública, pero según el proyecto podría hacérselo por resolución fundada del Subsecretario del Interior. La resolución debe apelarse en un plazo de 48 
horas máximo, e incluso se contempla el encarcelamiento del migrante mientras termina el proceso.

Ahora bien, la principal distancia entre el DL 1.094 y el proyecto de modificación presentado residiría, en teoría, en el reconocimiento de derechos a los migrantes - un reconocimiento limitado en todo caso, aunque la extensión de este artículo no nos permite detenernos en ello. El proyecto presentado por el entonces presidente Piñera incorporaría el enfoque de los derechos humanos, una perspectiva ausente del DL 1.094, como consecuencia evidente de su escenario de gestación. Sin embargo, tal como ocurre con la "gestión" de las migraciones en el marco de la gobernabilidad migratoria, el recurso a los derechos humanos opera como herramienta de legitimación - y, finalmente, como otra estrategia de control—. La prueba más contundente de ello aparecía en un párrafo que estaba contemplado en el primer borrador del texto, y que finalmente fue eliminado (aunque no su espíritu), seguramente por su poca sutileza política en el contexto internacional. El párrafo en cuestión, que aparecía en los argumentos del proyecto, decía: "La discusión en torno al tipo de política que los países diseñan suele partir de una distinción fundamental: la migración como un derecho humano o como un beneficio que los Estados, en el ejercicio de su soberanía, conceden a quienes cumplen con los criterios de admisión que han definido previamente. El proyecto de ley se inclina, en línea con la mayoría, por lo segundo" (énfasis en el original). La redacción actual del proyecto ya no hace explícita esta elección, y en cambio reconoce la igualdad de derechos con los chilenos: "el proyecto da un paso adelante respecto a la regulación actual, al relevar en forma explícita la condición de igualdad de los derechos de los migrantes para el caso general, listar las prerrogativas que les son propias por su naturaleza foránea y describir el piso mínimo garantizado para quienes permanecen en el territorio en condición irregular”. Sin embargo, en el mismo texto incluso se establecen categorías de esa "igualdad", tanto entre los propios migrantes como respecto de los nativos. Y muchas de las disposiciones contenidas en él representan violaciones flagrantes a los derechos humanos, como la detención de una persona por una contravención administrativa como la de ingresar al país por un paso no habilitado.

El análisis más minucioso de la norma permite ir desarticulando los engranajes de esta lógica general que he descrito, pero baste una cita más, que es muy significativa porque condensa con mucha nitidez los elementos del régimen de la gobernabilidad migratoria al que me he referido y que fundamenta este proyecto: "Para cumplir con estos objetivos [los de la ley en general] la reforma busca promover que los migrantes se constituyan en un aporte para el país, pero asumiendo la responsabilidad de proteger sus derechos y asegurar que la migración se realice de manera segura y regular, a través de un procedimiento informado y tendiente a su integración activa a la sociedad chilena”. Es decir, la lógica costo-beneficio, el binomio regularidad-seguridad y los derechos humanos como elemento legitimador, puestos al servicio de un régimen de control más eficaz y utilitarista de la migración. 


\section{Recapitulaciones y proyecciones}

Sin ánimo de abundar en argumentos que consideramos suficientemente desarrollados en el análisis, parece bastante clara la continuidad de la idea de seguridad en el pensamiento de Estado sobre las migraciones internacionales en Chile durante las últimas cuatro décadas, persistencia que ha ido coagulando de modos diversos en este lapso. Asumir esa persistencia adquiere una relevancia política ineludible en el contexto actual de discusión de un anteproyecto de ley de migraciones que no escapa a este hilo conductor, como aludimos en la introducción de este trabajo.

Ahora bien, excediendo el contexto chileno, cabría preguntarse, como se planteó en alguna de las instancias en que se compartieron versiones preliminares de este trabajo, si es posible pensar una política migratoria que no sea una política de control — entendiendo el control como la derivación lógica de vincular la migración con los asuntos de seguridad, lo que a su vez implica, en última instancia, pensar a la migración como un potencial peligro - . La evidencia empírica parecería responder que no, sin embargo, es preciso asumir y problematizar ese supuesto rasgo inherente de control de las políticas migratorias, puesto que se trata de una construcción histórica que emerge en el contexto específico, el de la gubernamentalidad liberal y su matriz biopolítica. Que sea el modo hegemónico en que hemos pensado las migraciones no significa que no existan otros modos en que la migración internacional pueda ser pensada, y abordada, desde el Estado.

¿Cuáles son esos otros modos posibles? Esa es la apuesta para la imaginación sociológica y política, sobre todo política, especialmente considerando que: "One aspect of securitization is the objectification of the migrant as one who has no political subjectivity" (Walters 2010). Recuperar esa subjetividad política, rompiendo con la unidimensionalización del migrante como sujeto económico que prima en el actual régimen internacional de control de las migraciones, es un asunto decisivo. Recuperar su autonomía y su capacidad de acción política. Y en este sentido, buena parte de la esperanza en un cambio en este sentido en el escenario chileno reside en la capacidad de organización y articulación de las organizaciones de migrantes. 


\section{Notas}

${ }^{1}$ Este trabajo ha sido elaborado en el marco del Proyecto Fondecyt $N^{\circ} 1140679$ "Estado chileno e inmigrantes latinoamericanos frente a frente: reconocimiento, respeto y expectativas de incorporación”. Se ha beneficiado además de los comentarios de compañeros del programa de investigación Multiculturalismo, migraciones y desigualdad en América Latina, del Centro de Estudios Avanzados y el Centro de Investigaciones y Estudios sobre Cultura y Sociedad de la Universidad Nacional de Córdoba, Argentina.

${ }^{2}$ Aunque por supuesto este no es el único factor que explica esta "instalación", es uno de los más importantes. Efectivamente, entre el censo de 1992 y el de 2002 la población migrante internacional de Chile creció un 76\%, cuando en la década anterior lo había hecho solo en un $25 \%$ —e incluso el crecimiento había sido negativo en los dos decenios anteriores-. El proceso se habría acentuado en la última década: según estimaciones del Departamento de Extranjería y Migración (DEM) y el INE, entre 2005 y 2014 la población migrante internacional creció un 193\% (DEM 2015). De hecho, después de haber sido considerado un país expulsor de población (Martínez Pizarro 2003), hoy se lo define como un país de inmigración neta (Thayer y Durán 2015). De todos modos, los migrantes internacionales no tienen un peso significativo sobre la población nacional $(2,3 \%)$.

${ }^{3}$ Esta referencia geográfica no es casual, en la medida que es en el norte del país donde las fronteras (las geopolíticas) se multiplican. Por otra parte, el contexto migratorio antofagastino tiene particularidades cuyo detalle excede los propósitos de este artículo, pero que agudizan la construcción de representaciones sociales que ligan la migración a la delincuencia, y a un aumento de los niveles de violencia de esa supuesta actividad delictual.

${ }^{4}$ Resulta además reveladora la consistencia de estas propuestas realizadas por legisladores con posiciones claramente diferentes dentro del espectro ideológico.

${ }^{5}$ En un contexto en el que además se han constatado arbitrariedades notorias en estos procesos de expulsión, como se ha encargado de demostrar a partir de varias causas la Defensoría Penal Pública.

${ }^{6}$ En el artículo 13 de este anteproyecto, por ejemplo, que es aquel en el que se reconoce el derecho a migrar, se aclara que: "El Estado es soberano para establecer limitaciones al ejercicio de este derecho necesarias en una sociedad democrática, para proteger la seguridad nacional, el orden público, la salud o moral pública y los derechos y libertades de toda persona”. La semejanza con la redacción del DL 1.094 es además notable. Y por otra parte, el proyecto revela una preocupación significativa por la expulsabilidad del migrante.

${ }^{7}$ El período fue determinado considerando el momento de gestación de la ley actualmente vigente y los gobiernos democráticos posteriores que han finalizado su mandato, dado que esa finalización habilita un análisis más conclusivo.

${ }^{8}$ Algunos de los argumentos que se desarrollan en este apartado y el próximo fueron planteados inicialmente en Stang (2012). También pueden consultarse algunas notas sobre la posibilidad de entender la gobernabilidad migratoria desde la perspectiva de la 
gubernamentalidad foucaultiana en Stang (2011).

${ }^{9}$ Entre 1960 y 1970 la proporción de población extranjera sobre la población nacional había decrecido en casi un 7\% (Martínez Pizarro 2003).

${ }^{10}$ Informe $\mathrm{N}^{\circ}$ 581, Remite Proyecto de Decreto Ley de Extranjería, Del asesor jurídico al Ministerio del Interior, 31 de octubre de 1974.

${ }^{11}$ Salvo que se especifique lo contrario, los énfasis en las citas son propios.

${ }^{12}$ La redacción actual es la que sigue: "Por decreto supremo podrá prohibirse el ingreso al país de determinados extranjeros por razones de interés o seguridad nacionales”.

${ }^{13}$ Orden $\mathrm{N}^{\circ} 275$, del 25 de febrero de 1975, por la cual se remiten al jefe de la Comisión de Asesoría y Coordinación Jurídica las observaciones del Ministerio del Interior al proyecto.

${ }^{14}$ La biopolítica, que constituye un elemento central de la noción foucaultiana de gubernamentalidad, alude a la "creciente implicación de la vida natural del hombre en los mecanismos y los cálculos del poder” (Agamben 2003:318). El liberalismo, como forma de condensación específica de esta gubernamentalidad, es "la forma de racionalidad propia de los dispositivos de regulación biopolítica” Senellart, 2007:440). La migración, en tanto proceso de circulación de la población, constituye un campo fundamental de intervención biopolítica en el marco de la gubernamentalidad liberal, y de condensación de las funciones de policía en que se traduce (o que la traducen). A partir de esa función el Estado se arroga el derecho de decidir quiénes y cuántos es conveniente que entren a su territorio y circulen por él, qué requisitos deberán cumplir para ajustarse a esos criterios de conveniencia (educativos, ocupacionales-económicos y hasta sanitarios), cuándo podrá expulsárselos, e incluso dónde podrán asentarse o a qué y por cuánto tiempo podrán dedicarse.

${ }^{15}$ Como ejemplo, véase [en línea] http://www.cajmetro.cl/noticias/corte-suprema-acogeamparo-de-oficina-de-derechos-humanos-de-corporacion-de-asistencia-judicial-metr/ , respecto de un recurso de amparo presentado por la Corporación de Asistencia Judicial de la Región Metropolitana por un caso en que se recurrió a este criterio para impedir el acceso de migrantes colombianos al país, y que fue acogido por la Corte Suprema en noviembre de 2014.

${ }^{16}$ La consideración de medidas para el retorno de los nacionales emigrados —especialmente aquellos que hubiesen obtenido cualificaciones consideradas útiles y provechosas, o los que tuvieren recursos para invertir - es un tema ausente en la normativa que este proyecto pretendía reemplazar. Su abordaje en este proyecto es consistente con este eje articulador que constituye la noción de desarrollo: "La política de retorno de nacionales residentes en el exterior procurará su reinserción en la sociedad chilena a fin de aprovechar, en beneficio de ambos, la capacidad profesional, la nueva cultura adquirida y la fuerza laboral que ellos representan” (artículo 6).

${ }^{17}$ La emergencia (o reemergencia en rigor) de la idea de la migración planificada parece estar conectada con la temprana incidencia de los organismos internacionales en la definición de las políticas migratorias nacionales, en este caso puntual, de la OIM. De hecho, la consideración de esta influencia aparece explícitamente en los argumen- 
tos del mensaje presidencial que antecede al proyecto (Mensaje 102/327): "se establece la importancia y trascendencia de los organismos nacionales e internacionales vinculados a este fenómeno. En este sentido, cabe destacar la participación de la Organización Internacional para las Migraciones, O.I.M., de la cual Chile es miembro, dada su competencia en el ámbito de las Migraciones Internacionales”. Sustentamos la idea de esta incidencia aparente en la semejanza con los argumentos que se proponen en un Programa operativo de migración planificada y selectiva desde los países de la CEI y Europa del Este hacia la Argentina, surgido de una asistencia técnica de la OIM a ese gobierno en 1992. En ese documento se desarrollan los argumentos del organismo respecto de los beneficios de una migración selectiva y dirigida territorialmente, y se sostiene que"es indispensable que los procesos migratorios se encuadren dentro del proyecto nacional deseado, del cual deben ser un instrumento", pues de lo contrario los resultados pueden ser catastróficos. El énfasis en la necesidad de la regulación también emerge con claridad: "es indispensable definir claramente y desde el principio cuáles serán las características de la migración y las reglas del juego que la regirán”.

${ }^{18}$ Este instructivo reconoce como antecedente un texto elaborado por una comisión de política migratoria creada durante el gobierno del presidente Ricardo Lagos (20002006), que resumía la visión del gobierno sobre el fenómeno de las migraciones (Departamento de Extranjería y Migración, 2007).

${ }^{19}$ Solo a título de ejemplo, en un documento del Departamento de Extranjería y Migración de 2007, publicado en su sitio web, se sostenía que: "La visión del Gobierno de Chile en materia migratoria se enfoca a regular la inmigración de manera que beneficie tanto a los inmigrantes como a las comunidades de origen”.

${ }^{20}$ Proceso extraordinario de regularización migratoria iniciado el 5 de noviembre de 2007 y que se extendió hasta el 5 de febrero de 2008.

21 "The flip side of the necessity of defining the limits of freedom is the constant concern with security”, sostiene Sara Kalm (2008:158) en un trabajo en el que explora la función reguladora delas políticas globales de migración como un caso especial de gubernamentalidad foucaultiana; "to Foucault, this art of government [el liberal] is continuously concerned with arbitrating the limits between freedom and security".

22 Sin embargo, el texto de la norma desconoce varios compromisos internacionales adquiridos por Chile en materia de derechos de las personas migrantes (CDH-UDP 2013).

${ }^{23} \mathrm{Al}$ iniciar su mandato, el gobierno de Sebastián Piñera no manifestó su intención de revisar el marco jurídico en relación con la migración (CDH-UDP 2011); es más, el propio presidente sostuvo que lo que haría su gobierno en el área migratoria sería “respetar la legislación vigente" (Stefoni 2011: 83). Sin embargo, hacia el final de su mandato las voces empresariales reclamando la escasez de mano de obra no calificada empezaron a hacerse oír en ciertos medios, en paralelo al impulso de la iniciativa de modificación del DL 1.094 . 


\section{Bibliografía}

Abramovich, V. (2006), “Una aproximación al enfoque de derechos en las estrategias y políticas de desarrollo”, Revista de la CEPAL 88, Santiago.

Agamben, G. (2003),Homo sacer. El poder soberano y la nuda vida, PreTextos, Valencia.

Ansaldi, W. (2004), "Matriuskas del terror. Algunos elementos para analizar la dictadura argentina dentro de las dictaduras del Cono Sur", en Pucciarelli, A. (coord.), Empresarios, tecnócratas y militares. La trama corporativa de la última dictadura, Siglo XXI, Buenos Aires.

Ansaldi, W. y Giordano, V. (2012), América Latina. La construcción del orden, Ariel, Buenos Aires, 2 tomos.

Arriagada, G. (1998), Por la razón o por la fuerza. Chile bajo Pinochet, Sudamericana, Santiago.

CDH-UDP (Centro de Derechos Humanos de la Universidad Diego Portales) (2013), Informe anual sobre derechos humanos en Chile 2013, Santiago.

Ídem (2011), Informe anual sobre derechos humanos en Chile 2010, Santiago.

Ídem (2010), Informe anual sobre derechos humanos en Chile 2009, Santiago.

Ídem (2008), Informe anual sobre derechos humanos en Chile 2007. Hechos 2006, Santiago.

Ídem (2007), Informe anual sobre los derechos humanos en Chile 2006, Santiago.

Ídem (2006), Informe anual sobre derechos humanos en Chile 2005, Santiago.

Ceriani, P.; Courtis, C.; Pacecca, M. I.; Asa, P. y Pautassi, L. (2009), “Migración y trabajo doméstico en Argentina: las precariedades en el marco global”, en OIT, Valenzuela, M.E. y Mora, C., Trabajo doméstico: un largo camino hacia el trabajo decente, OIT, Santiago.

DEM (Departamento de Extranjería y Migración)(2015), Migración en Chile 2005-2014, Santiago.

Ídem (2007), “Evolución de la gestión gubernamental desde 1990: Desarrollo del fenómeno de las migraciones en Chile”, Santiago, mimeo. 
Domenech, E.(2015), “O controle da imigração “indesejável”: expulsão e expulsabilidade na América do Sul”, Ciência e Cultura, vol. 67, no. 2, Apr./ June, São Paulo.

Ídem (2013), “'Las migraciones son como el agua’: Hacia la instauración de políticas de ‘control con rostro humano’. La gobernabilidad migratoria en la Argentina”, Polis [En línea], 35, consultado el 27 diciembre 2014.

Ídem (2011), “La gobernabilidad migratoria en la Argentina: hacia la instauración de políticas de control con “rostro humano”“, IV Congreso de la Red Internacional de Migración y Desarrollo, Quito.

Foucault, M. (2008), El nacimiento de la biopolítica, Fondo de Cultura Económica, Buenos Aires.

Ídem (2007), Seguridad, territorio, población, Fondo de Cultura Económica, Buenos Aires.

Gazmuri, C. (2003), “Una interpretación política de la experiencia autoritaria (1973-1990)”, en La dictadura militar chilena, 1973-1990, Documento de trabajo 10, Serie III, Unidad de Docencia e Investigación Sociohistórica, Buenos Aires.

Kalm, S. (2008), Governing Global Migration, Lund Political Studies 153, Department of Political Science, Lund University, Lund.

Martínez, J. (2003), "El encanto de los datos. Sociodemografía de la inmigración en Chile según el censo 2001”, serie Población y Desarrollo Nº 49, CEPAL, Santiago.

Moreira, M. H. (s/f), “A Doutrina de Segurança Nacional e Desenvolvimento”, mimeo.

Pinochet, A. (1983), Geopolítica de Chile, Buenos Aires, El Cid.

Senellart, M. (2007), “Situación de los cursos”, en Foucault, M., Seguridad, territorio, población, Fondo de Cultura Económica, Buenos Aires.

Stefoni, C. (2011), “Ley y política migratoria en Chile. La ambivalencia en la comprensión del migrante”, en Bela-Feldman y otros (comps.), La construcción social del sujeto migrante en América Latina. Prácticas, representaciones y categorías, FLACSO, Sede Ecuador/CLACSO/Universidad Alberto Hurtado, Quito.

Stang, M.F. (2012), "Estado y migración internacional en el Chile de la posdictadura: una relación con cara de Jano”, Revista de Paisajes Áridos y Semiáridos, Año IV, Volumen VI, Universidad Nacional de Río Cuarto, Río Cuarto. 
Ídem (2011), "Notas para pensar la gobernabilidad migratoria desde la noción foucaultiana de gubernamentalidad”, Santiago, mimeo, [en línea] https:/ /www.academia.edu/6727331/Notas_para_pensar_la_gobernabilidad _migratoria_desde_la_noci\%C3\%B3n_foucaultiana_de_gubernamentalidad.

Thayer, E. y Durán, C. (2015), “Gobierno local y migrantes frente a frente: nudos críticos y políticas para el reconocimiento”, Revista del CLAD Reforma y Democracia 63.

Velásquez, É. (2002), “Historia de la Doctrina de la Seguridad Nacional”, Convergencia, enero-abril, año 9, número 27, Universidad Autónoma del Estado de México, Toluca.

Walters, W. (2010), "Migration and Security”, in Burgess, J. P. (ed.), The Handbook of New Security Studies, Routledge, London.

Recibido: 01.07.16

Aceptado: 30.07.16 